\title{
Corrigendum: Rare coding variants and X-linked loci associated with age at menarche
}

Kathryn L. Lunetta, Felix R. Day, Patrick Sulem, Katherine S. Ruth, Joyce Y. Tung, David A. Hinds, Tõnu Esko, Cathy E. Elks, Elisabeth Altmaier, Chunyan He, Jennifer E. Huffman, Evelin Mihailov, Eleonora Porcu, Antonietta Robino, Lynda M. Rose, Ursula M. Schick, Lisette Stolk, Alexander Teumer, Deborah J. Thompson, Michela Traglia, Carol A. Wang, Laura M. Yerges-Armstrong, Antonis C. Antoniou, Caterina Barbieri, Andrea D. Coviello, Francesco Cucca, Ellen W. Demerath, Alison M. Dunning, Ilaria Gandin, Megan L. Grove, Daniel F. Gudbjartsson, Lynne J. Hocking, Albert Hofman, Jinyan Huang, Rebecca D. Jackson,

David Karasik, Jennifer Kriebel, Ethan M. Lange, Leslie A. Lange, Claudia Langenberg, Xin Li, Jian'an Luan, Reedik Mägi, Alanna C. Morrison, Sandosh Padmanabhan, Ailith Pirie, Ozren Polasek, David Porteous, Alex P. Reiner, Fernando Rivadeneira, Igor Rudan, Cinzia F. Sala, David Schlessinger, Robert A. Scott, Doris Stöckl, Jenny A. Visser, Uwe Völker, Diego Vozzi, James G. Wilson, Marek Zygmunt, EPIC-InterAct Consortium, Generation Scotland, Eric Boerwinkle, Julie E. Buring, Laura Crisponi, Douglas F. Easton, Caroline Hayward, Frank B. Hu, Simin Liu, Andres Metspalu, Craig E. Pennell, Paul M. Ridker, Konstantin Strauch, Elizabeth A. Streeten, Daniela Toniolo, André G. Uitterlinden, Sheila Ulivi, Henry Völzke, Nicholas J. Wareham, Melissa Wellons, Nora Franceschini, Daniel I. Chasman, Unnur Thorsteinsdottir, Anna Murray, Kari Stefansson, Joanne M. Murabito, Ken K. Ong \& John R.B. Perry

Nature Communications 6:7756 doi: 10.1038/ncomms8756 (2015); Published 4 Aug 2015; Updated 17 Dec 2015

In the Results section and in the legend of Table 1 of this Article, the company deCODE genetics, Inc. is incorrectly referred to as 'Diabetes Epidemiology: collaborative analysis of Diagnostic criteria in Europe'. In neither instance is deCODE an abbreviation.

\footnotetext{
(c) (i) This work is licensed under a Creative Commons Attribution 4.0 International License. The images or other third party material in this article are included in the article's Creative Commons license, unless indicated otherwise in the credit line; if the material is not included under the Creative Commons license, users will need to obtain permission from the license holder to reproduce the material. To view a copy of this license, visit http://creativecommons.org/licenses/by/4.0/
} 